\title{
Aiding the cleaning of four 19th-century Tsimshian house posts: investigation of museum-applied surface coatings and original polychromy
}

Federica Pozzi ${ }^{i^{*}} \mathbb{0}$, Elena Basso ${ }^{1}$, Samantha Alderson², Judith Levinson², Madeleine Neiman ${ }^{3}$ and Soraya Alcalá ${ }^{4}$

\begin{abstract}
The collection of the American Museum of Natural History, New York, includes a set of four elaborately painted 19th-century Tsimshian house posts that have been on continuous open display for more than a century. Over time, these objects have accumulated surface grime, and several coating layers applied in undocumented past restoration campaigns, some of which have yellowed with age. The combination of heavy soiling and multiple coatings has obscured the underlying polychromy, shifting the colors of the wood and paints, and yielding improper surface appearances. Further, some of the coatings appeared to have sunk into the media-lean paints, complicating removal. Questions regarding the number, types, and timing of coating applications, as well as the nature of some of the paint below, set the stage for an in-depth technical study aiming to inform the conservation treatment of these poles being undertaken in connection with the renovation of the Northwest Coast Hall at the museum. Microscopic examination of numerous cross sections removed from the four house posts under polarized and ultraviolet (UV) illumination shed light on the number of coating layers present in selected areas and their location in relation to the overall stratigraphy. Micro-invasive analysis of samples relied on a combination of spectroscopic and chromatographic techniques, including transmission Fourier-transform infrared (FTIR) spectroscopy, attenuated total reflection (ATR)-FTIR spectroscopy, and pyrolysis-gas chromatography/mass spectrometry (Py-GC/MS), aiming to determine the exact chemical composition of the coatings. Portable X-ray fluorescence (XRF), FTIR, Raman, and scanning electron microscopy with energydispersive $X$-ray spectroscopies (SEM/EDS) provided insight into the color palette used, with a focus on green paints. Investigation of the coatings revealed the application of multiple layers, including cellulose nitrate and localized areas of polyvinyl acetal. Analysis of the paint identified a limited range of inorganic pigments and, additionally, assisted in tackling issues that arose during the cleaning of specific colored areas. Results from this technical study helped address outstanding questions regarding this group of historical Tsimshian house posts, informing the development of a suitable treatment tailored to the safe removal or reduction of surface coatings and grime, ultimately improving the legibility of the design and colors.
\end{abstract}

Keywords: House posts, Totem poles, Tsimshian, Pacific Northwest, 19th century, Wood, Coatings, Polychromy, Cleaning treatment

\footnotetext{
*Correspondence: federica.pozzi@metmuseum.org

${ }^{1}$ Department of Scientific Research, The Metropolitan Museum of Art,

1000 Fifth Avenue, New York, NY 10028, USA

Full list of author information is available at the end of the article
}

\section{Introduction}

The Northwest Coast Hall at the American Museum of Natural History (AMNH), New York, is the museum's oldest hall. Installed under the supervision of the influential anthropologist Franz Boas, it opened in 1899 and 
displays a selection of objects from the communities indigenous to the Pacific Coast of North America. Until a major renovation began in 2017, the Hall had remained largely unchanged for more than a century, featuring, among other treasures, 77 large-scale wooden carvings on continuous open display. The monumental carvings of the Northwest Coast are often collectively referred to as "totem poles". However, "totem" originates from a different culture and geographic area: it is an Ojibwe (Anishinaabemowin) term of the Great Lakes region and the Algonguian language family, referring to a clan emblem or individual guardian spirit. As such, its colonial application to Northwest Coast monumental carvings is incongruous and ethnographically inaccurate [1]. Northwest Coast poles and other carvings may represent lineage crests and rights, or ancestral narratives associated with particular hereditary chiefs or "houses" [2]. Significations also differ internally among Northwest Coast nations depending in part on their respective kinship systems (matrilineal, patrilineal, or bilateral) and ceremonial emphases. The term "totem pole" conflates several distinct types of carvings, including house frontal poles, interior house posts, mortuary, memorial, and welcome poles and figures [3].

The focus of the present article is a set of four poles $(16 / 565,16 / 566,16 / 567$, and 16/568) of the Tsimshian nation of northern British Columbia and Alaska (Fig. 1). In form, these poles most closely resemble house posts that would have been placed in the interior of a large traditional longhouse supporting the roof [3]. Each of the four house posts, approximately 15 feet tall and depicting a series of stacked anthropomorphic and zoomorphic figures or crests, is probably associated with one of the four main Tsimshian matrilineal groups: Lax-ski'ok, "Eagle group"; Lax-k'ebo, "Wolf group"; Ganha'da, "Raven group"; and Gispawadwe'da, "Bear group" (Sm'álgyax [Tsimshian language] terms are here simplified from Boas' orthography) $[4,5]$. Collector Israel Powell, Superintendent of Indian Affairs for British Columbia, cited the four clan "heraldic" associations of the Tsimshian house posts in letters and other records sent to AMNH Curator Alfred Bickmore [Whiteley P. Notes on the Bishop-Powell Collection, Tsimshian house-posts (16/565-16/568), "Haida" carving (16/570), and the great canoe. Internal report, American Museum of Natural History, 2018, unpublished].

Beginning in the late 1990s, AMNH conservators undertook condition surveys of the monumental carvings in the Northwest Coast Hall, bringing to light the widespread need for treatment of this important collection. This prompted a multiyear conservation endeavor, whose initial phases focused on structural issues of the

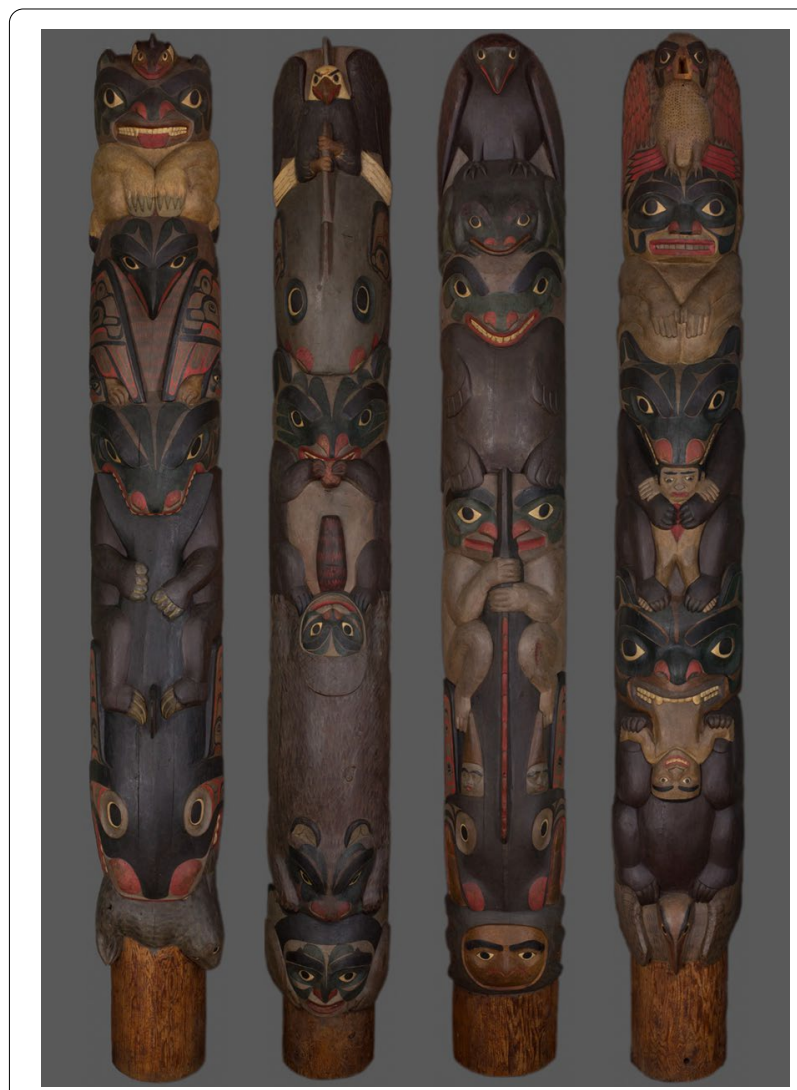

Fig. 1 The AMNH Tsimshian house posts, frontal view, after conservation treatment $(16 / 565,16 / 566,16 / 567$, and 16/568 from left to right). Taken in 2019 by Craig Chesek @AMNH Photo Studio

wood, as many carvings exhibited rot, splits, splintering, and other forms of instability-so fragile that even gentle dusting carried out as part of ongoing housekeeping caused damage [6]. The work also revealed the extent and complexity of the surface issues present.

The surfaces of the four Tsimshian house posts were less weathered than many others in the Hall. This is attributable to several factors, including possible intended use as interior house posts or the fact that they were collected soon after fabrication. Still, the surfaces had suffered significant damage over time from environmental exposure and human interventions. Physical damages, including surface abrasions, likely occurred during transport across the continent and multiple installations in the museum before placement in their current location in the Hall. The lower sections of the poles have been within easy reach, resulting in further damage from burnishing, scratching, graffiti, and deposits of chewing gum. For several decades after they arrived at the AMNH around 1882, the house posts were displayed next to large windows (Fig. 2) and, for many following, they have been 


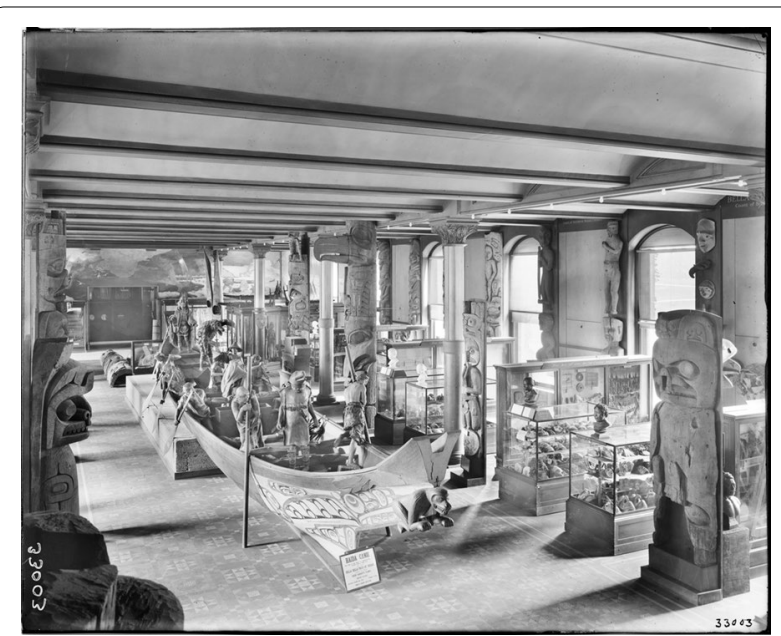

Fig. 2 The Northwest Coast Hall at AMNH, ca. 1910. Image \#33003, American Museum of Natural History Library. The image shows many monumental carvings installed in the Hall when coal heating and open windows were a source for heavy soot deposits. Two of the Tsimshian house posts in this study (16/565 and 16/568) are mounted on the wall just beyond the third large window

adjacent to HVAC vents. Before 1995, the Hall had no climate control, and the collection was exposed to the full range of widely fluctuating environmental conditions typical of the Northeast. Historically, the presence of an on-site incinerator, coal heating, as well as urban and industrial activities, produced black sooty residues that covered the objects. Although these sources have been eliminated or reduced over the years, rapid accumulation of dust persists due to the high attendance numbers at the museum. Dust and grime have been compacted and sealed on the fragile painted surfaces over the decades by numerous largely undocumented campaigns of cleaning and coating. Soiling was trapped on the surface over, as well as under and between, multiple coating layers. Cleaning tests indicated that removal or reduction of these materials would pose a complex challenge, given the fragile deteriorated wood and sensitivity of the under-bound and damaged original paint. The accumulations of soiling and coatings strongly impacted the appearance of all the carvings in the Hall-all were darker, and many shinier than they would have originally appeared. Those with the most extensive remaining paint were most severely affected, with the original designs and colors significantly obscured.

During 2017, in conjunction with a complete renovation of the Northwest Coast Hall, a new conservation campaign was undertaken, focused on cleaning six carvings with the most complex polychromy, including the four Tsimshian house posts in this study. These are the most intricately carved and painted poles in the collection and are among the earliest museum accessions. This project was headed by a team of conservators at the $\mathrm{AMNH}$ and included collaborative work with several constituencies. Collaboration with First Nations communities on the Hall renovation, including the appointment of Co-Curator Haa'yuups (Ron Hamilton) and nine advisors for individual cultural groups, provided an opportunity to consult with David Boxley (Tsimshian Consulting Curator), Laurel Smith Wilson (Gitxsan Consulting Curator), and others regarding iconography, details of the carvings and polychromy, and determining the appropriate level of treatment.

Scientific studies of historic poles are very limited, both in terms of investigation of museum-applied coatings and analysis of their painted surfaces. The Canadian Conservation Institute (CCI), Ottawa, has reported the most extensive instrumental analysis of Northwest Coast painted surfaces to date, including an unpublished report of a project encompassing analysis of more than 1000 paint samples from many indigenous Canadian groups, among which 583 samples are from the Northwest Coast, for characterization of pigments and binding media [7]. A later article also from CCI focused on the identification of green pigments-particularly green earth (celadonite)-in Haida, Tlingit, and Tsimshian art [8]. It does not appear that any of the samples in the CCI studies were removed from poles or other monumental works, which may have differed in techniques and materials used due to their size and frequent outdoor installation. In addition, while there are a few accounts of museum-applied coatings found on poles in other collections, none of them reports the scientific analysis of these materials [9].

In this project, technical examination and scientific analysis, focusing on supporting efforts to clean the four AMNH Tsimshian house posts, aimed to address questions about the number, composition, and timing of coating applications, as well as specific queries regarding the nature of the polychromy. After an initial close visual inspection and non-invasive analysis, limited sampling and micro-invasive investigations were carried out concurrently with the cleaning of the poles and as questions arose during the conservation treatment. This data informed the development of suitable cleaning methods, whose application greatly improved the legibility of the design and colors of these carvings without damaging the underlying paint layers.

\section{Experimental}

The present research relied on scientific analysis employing non-invasive and micro-invasive techniques, performed, respectively, in the Northwest Coast Hall of the 
AMNH and in the Department of Scientific Research (DSR) of The Metropolitan Museum of Art (The Met). After an initial assessment of the poles' surfaces under visible and ultraviolet (UV) illumination, portable X-ray fluorescence (XRF) spectroscopy was used to determine the elemental composition of the main paints applied to house posts $16 / 565,16 / 566,16 / 567$, and 16/568. Subsequently, eleven samples were removed from these four carvings with a scalpel, including scrapings targeting the coating layers above the paint and cross sections down to the underlying wood (Table 1). Ten of these samples were collected before treatment to study the coatings visible on the surface prior to cleaning. Among these, seven specimens were removed from areas that displayed a milky-white UV-induced fluorescence, where the uppermost coating layer was assumed to be cellulose nitrate $(\mathrm{CN})$ based on previous examination and analysis of other carvings in the Hall [6]. Most of these samples were taken from locations with dark colors of paint (blacks, browns, grays, and greens), where conservators had difficulty determining if any pigment was being lifted during initial cleaning tests and were hoping to gain a better understanding of the coating/paint interface. Three samples were collected from locations where an additional coating layer displaying a bright blue-white UV-induced fluorescence was found; two were from the bottom unpainted sections of these poles and one from a painted area near the bottom of one pole. The eleventh sample was removed to investigate an underlying organic layer with a weak dull yellow UV-induced fluorescence uncovered after partial cleaning. The cross sections were examined with polarized and UV illumination microscopy to shed light on the number of coating layers present in selected areas and to reveal how such coatings were intermixed with dirt and paint. Micro-invasive analysis of cross sections and scrapings removed from coated areas was conducted using transmission Fourier-transform infrared (FTIR) spectroscopy, attenuated total reflection (ATR)-FTIR spectroscopy, and pyrolysis - gas chromatography / mass spectrometry (Py-GC/MS) to provide insight into the chemical composition of the coatings. Two reference materials, namely a polyvinyl acetal (PVAcet) resin (Alvar) and a wood hardener (Xylamon) historically used in treatments at the AMNH, were also fully characterized with the same instrumental techniques for comparison. Further investigations with FTIR, Raman, and scanning electron microscopy with energy-dispersive $\mathrm{X}$-ray spectroscopies (SEM/EDS), as well as high-performance liquid chromatography with photodiode array detection (HPLC-PDA), involved the analysis of twelve additional samples taken from various areas of polychromy to address specific questions that arose as the conservation treatment progressed (Table 2). Three types of dye extraction, based on the use of various reagents, were tested prior to HPLC-PDA [10-12]; however, analysis was inconclusive. Most of these samples were collected from areas of green paint, as this color presented conservators with the greatest challenge when assessing the appropriate cleaning level and methods. Samples were also removed from two regions where cracks had been filled to help determine if the overlying paint was original or a later addition. Cross sections had an average area of $0.5-1.2 \mathrm{~mm}^{2}$, while scrapings were removed in the amount of 50-200 $\mu$ g. Exact sampling locations are indicated in Additional file 1: Figure S1. Experimental conditions for the analytical techniques employed are reported below.

$X R F$ Analysis was performed using a handheld Bruker Tracer III-SD analyzer with a $10-\mathrm{mm}^{2}$ silicon drift detector (SDD) and an average resolution of approximately $145 \mathrm{eV}$ for the full width at half maximum of the manganese (Mn) $\mathrm{K} \alpha$ line. The system is also equipped with changeable filters and a rhodium ( $\mathrm{Rh}$ ) transmission target with maximum voltage of $40 \mathrm{kV}$. Analysis was performed with $40-\mathrm{kV}$ voltage, $13-\mu \mathrm{A}$ current, 60 -s acquisition time, and no filter or vacuum was used, by positioning the instrument directly onto the object's surface after dry cleaning. X-ray beam size for the analyzed spot measures approximately $3 \times 4 \mathrm{~mm}$. The spectra were examined using the Artax software upon application of a standard Bayesian deconvolution method.

FTIR Analysis was carried out in transmission mode with a Hyperion 3000 FTIR spectrometer equipped with a mercury cadmium telluride (MCT) detector. For measurements in transmission, each sample was crushed in a Spectra Tech diamond anvil cell and all paint and coating layers contained in it were analyzed as a bulk through a $15 \times$ objective. For ATR measurements, each coating layer in the cross sections was analyzed individually with a $20 \times$ ATR objective featuring a germanium crystal. In both cases, spectra were collected in the $4000-600 \mathrm{~cm}^{-1}$ range at a resolution of $4 \mathrm{~cm}^{-1}$ as the sum of 128 or 256 scans, depending on the response of each area or sample examined. Spectra were interpreted by comparison with published literature and library databases available at The Met's DSR.

Raman Analysis was conducted using a Bruker Senterra Raman spectrometer equipped with an Olympus $50 \times$ long working distance microscope objective and a charge-coupled device (CCD) detector. A continuous wave diode laser, emitting light at $785 \mathrm{~nm}$, was used as the excitation source, and two holographic gratings (1800 and 1200 rulings $/ \mathrm{mm}$ ) provided a spectral resolution of $3-5 \mathrm{~cm}^{-1}$. The output laser power, number of scans, and integration time were adjusted 


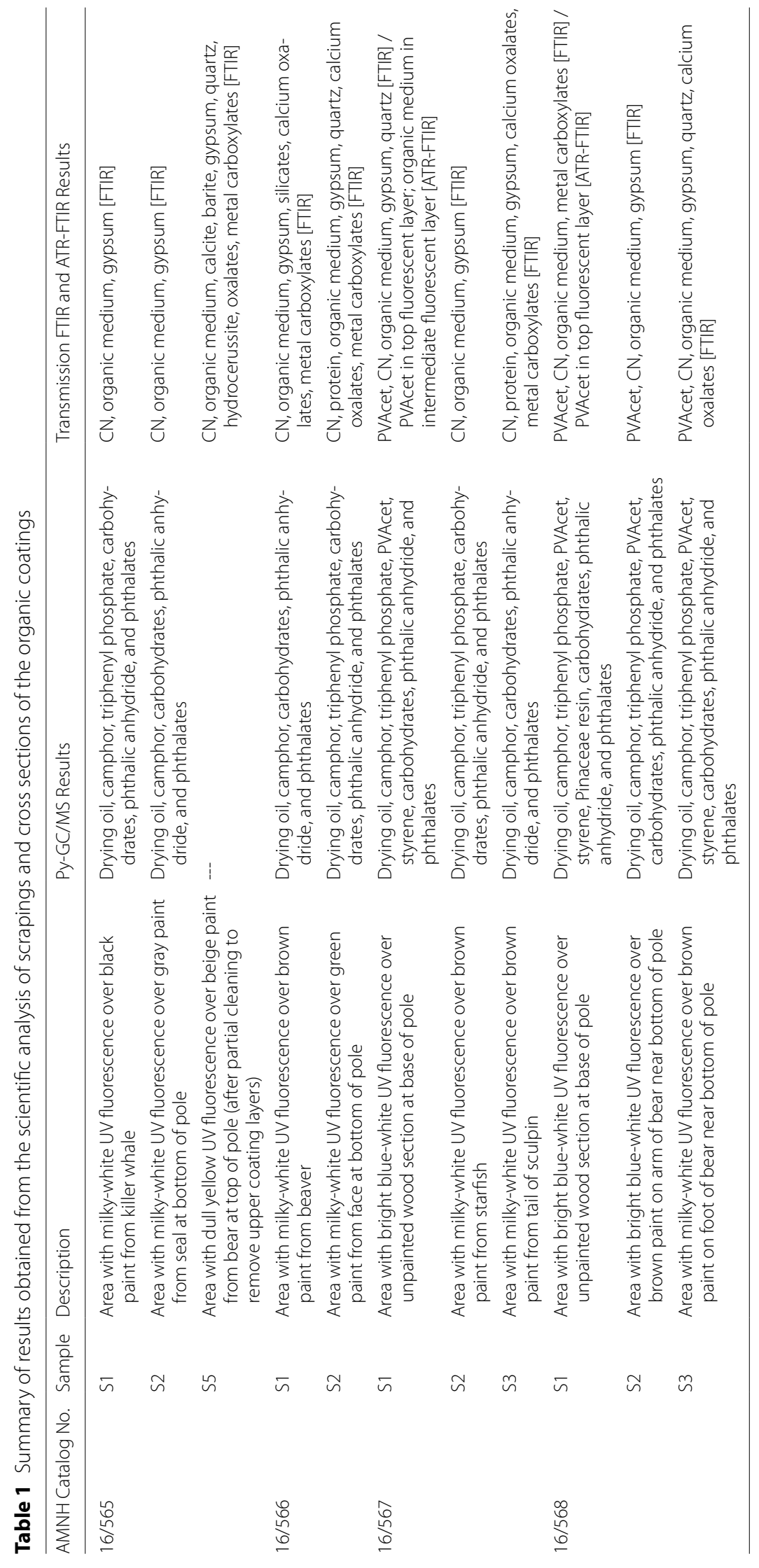


to prevent damage from overheating and according to the Raman response of the areas or samples examined. Spectra were interpreted by comparison with published literature and library databases available at The Met's DSR.

SEM/EDS Analysis was performed with a FE-SEM Zeiss $\Sigma$ igma HD system equipped with an Oxford Instrument X-MaxN 80 SDD. Back-scattered electron (BSE) imaging, as well as EDS elemental spot analysis and mapping, were performed in high vacuum at $20 \mathrm{kV}$, on $12-\mathrm{nm}$ carbon-coated samples.

$P y$-GC/MS Analysis was conducted on an Agilent 6890 gas chromatograph equipped with a Frontier PY-2020iD Double-Shot vertical furnace pyrolyzer fitted with an AS1020E Auto-Shot autosampler. The GC was coupled to a $5973 \mathrm{~N}$ single quadrupole mass selective detector (MSD). Samples of 30-50 $\mu \mathrm{g}$ were weighed out in deactivated pyrolysis sample cups (PY1-EC80F Disposable Eco-Cup LF) on a Mettler Toledo UMX2 Ultra microbalance. Samples were then either pyrolyzed without derivatization or derivatized with tetramethyl ammonium hydroxide (TMAH) before pyrolysis. Derivatization took place in the same cups as follows: $3-4 \mu \mathrm{L}$ of $25 \%$ TMAH in methanol (both from Fisher Scientific), depending on the sample size, were added directly to the sample in each cup with a $50-\mu \mathrm{L}$ syringe and, after $1 \mathrm{~min}$, loaded onto the autosampler. The interface to the GC was held at $320^{\circ} \mathrm{C}$ and purged with helium for $30 \mathrm{~s}$ before opening the valve to the GC column. The samples were then dropped into the furnace and pyrolyzed at $550{ }^{\circ} \mathrm{C}$ for $30 \mathrm{~s}$. The pyrolysis products were transferred directly to a DB-5MS capillary column $(30 \mathrm{~m} \times 0.25 \mathrm{~mm} \times 1 \mu \mathrm{m})$ with the helium carrier gas set to a constant flow of $1.5 \mathrm{~mL} / \mathrm{min}$. Injection with a 30:1 split was used, in accordance with the sample size. The GC oven temperature program was $40^{\circ} \mathrm{C}$ for $1 \mathrm{~min} ; 10{ }^{\circ} \mathrm{C} / \mathrm{min}$ to $320{ }^{\circ} \mathrm{C}$; isothermal for $1 \mathrm{~min}$. The Agilent 5973 N MSD conditions were set as follows: transfer line at $320^{\circ} \mathrm{C}$, MS Quad $150{ }^{\circ} \mathrm{C}$, MS Source $230{ }^{\circ} \mathrm{C}$, electron multiplier at approximately $1770 \mathrm{~V}$; scan range 33-550 amu. For samples run with TMAH, the detector was turned off until $3 \mathrm{~min}$ to avoid saturation by excess of derivatizing agent and solvent. Data analysis was performed on an Agilent MSD ChemStation D.02.00.275 software by comparison with the NIST 2005 spectral libraries.

Preparation of cross sections Cross sections were prepared by embedding each sample within a double layer of methyl methacrylate resin (Technovit ${ }^{\circledR} 2000$ LC). Each layer of resin was cured under UV light for $20 \mathrm{~min}$. Excess resin was ground off and the surface was finely polished using CarbiMet 2 and Micro-mesh abrasive paper of various grits to expose the samples' stratigraphy.

\section{Results and discussion Coatings}

A summary of the results obtained from the scientific analysis of the coatings and other organic materials found on the four house posts in this study is provided in Table 1.

$\mathrm{CN}$ is ubiquitous in the eleven samples examined. This resin has a long history of use in the treatment of art objects, antiquities, and natural science materials in museums $[13,14]$ and is known to have been employed widely on collection materials at the AMNH in the past. Aging studies have shown that $\mathrm{CN}$ is unstable, darkening significantly over time. This degradation process was at least partially responsible for the alteration of the painted surface observed in the present study.

Among the techniques used in this work, conclusive identification of $\mathrm{CN}$ could only be achieved by transmission FTIR (Fig. 3a), as its pyrolysis products cannot be detected by Py-GC/MS within the mass range scanned in our experiments [15]. In the data collected, an increased absorbance of the carbonyl bond in the $1718-1724 \mathrm{~cm}^{-1}$ range compared to reference spectra of pure, unaltered $\mathrm{CN}$ may point to a degradation process [16], as well as to contributions from additional components, possibly including oil, natural resins, or phthalates. Other compounds found in the chromatograms of nearly the totality of samples include camphor, typically present in significant amounts, as well as triphenyl phosphate and phthalates, detected in trace levels (Fig. 4). While the phthalates may also be interpreted as environmental contaminants, all these substances are reported as plasticizers for the $\mathrm{CN}[13,14,17]$. Often several plasticizers are used concurrently, some of which may also serve the purpose of flame retardants for the highly flammable synthetic polymer [18].

The widespread finding of $\mathrm{CN}$ in all areas sampled is associated with a milky-white UV-induced fluorescence emission, which only in certain regions displays a slight yellow-green tonality that is more in line with observations reported in the literature [19]. UV examination revealed that $\mathrm{CN}$ is applied overall to the front of these and all other large carvings in the Northwest Coast Hall, appearing as an uneven, drippy layer (or layers) (Fig. 5a). In most of the cross sections inspected, $\mathrm{CN}$ is visible as a discrete layer under UV illumination, clearly distinguishable, for example, in S2 from 16/565, S1 and S2 from 16/566, as well as S1 and S3 from 16/567 (Fig. 5b). In all these samples, however, the extreme thinness of these organic layers, averaging a few microns, prevented successful identification of this resin within the stratigraphy by ATR-FTIR due to frequent contamination from adjacent materials and from the embedding methyl methacrylate. 

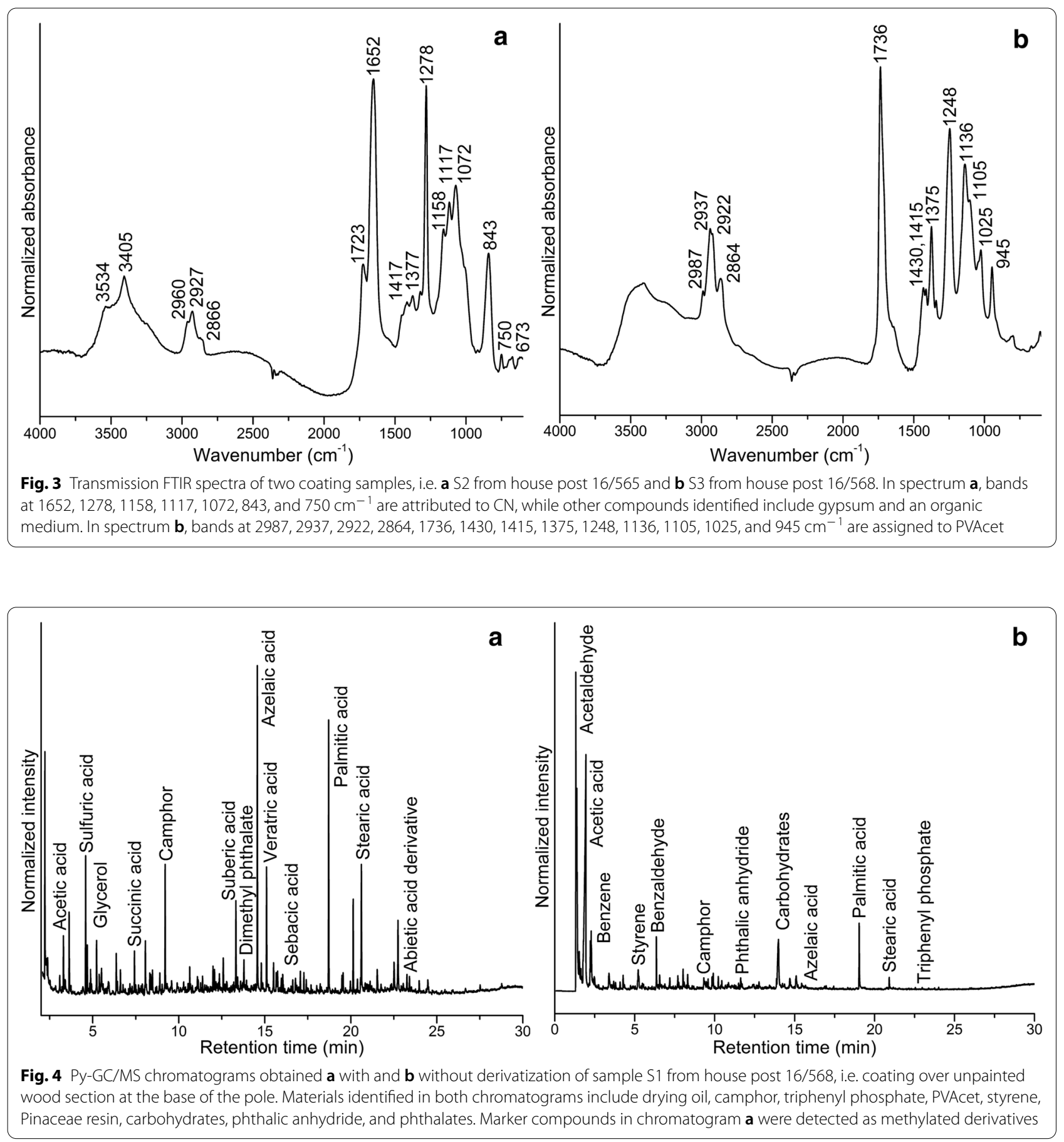

High quantities of acetic acid and benzene, along with various aldehydes such as acetaldehyde and benzaldehyde, were also identified in the chromatograms of numerous samples from two of the house posts, namely S1 from 16/567 as well as S1, S2, and S3 from 16/568 (Fig. 4). These series of components are consistent with the fragmentation pattern of PVAcet [20], whose presence was also corroborated by the detection of its strong, typical bands in transmission FTIR spectra (Fig. 3b). In all cases, PVAcet was detected alongside styrene, which was also found to be part of the formulation of the reference Alvar sample analyzed for comparison and may thus be interpreted as a copolymer likely added as an internal plasticizer. Polyvinyl acetal resins, primarily 


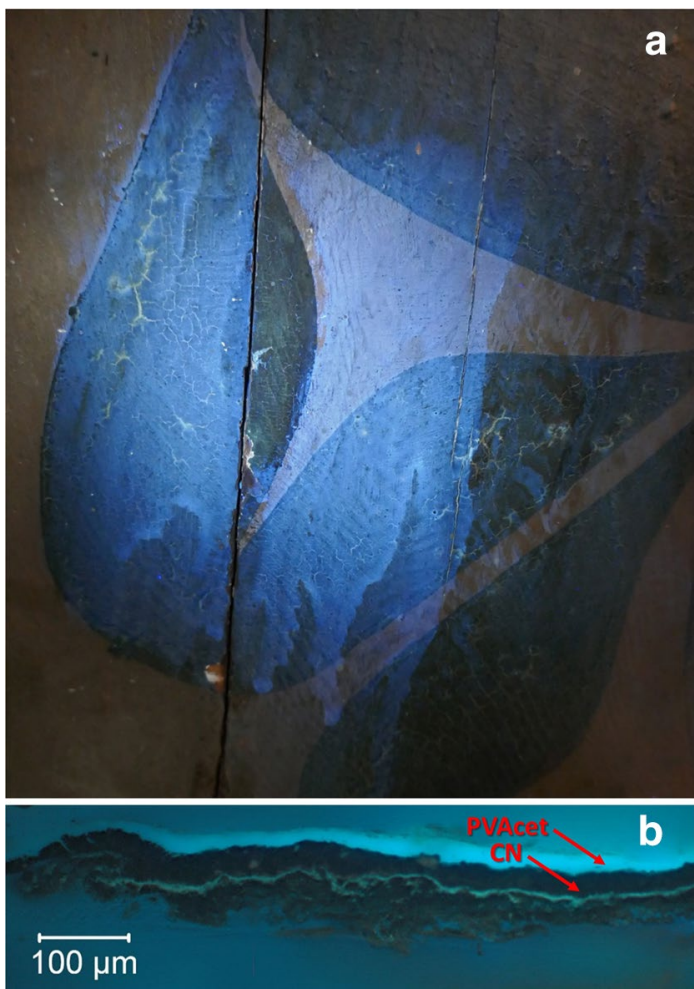

Fig. 5 a Detail of middle bear figure on house post 16/565 under UV illumination, in which CN application displays a milky-white fluorescence emission. The photograph was taken during cleaning with CN removed from the half-oval at center. b UV light microphotograph of cross section S1 from house post 16/567, where $\mathrm{CN}$ is visible as a discrete, thin layer on the wood under layers of museum-applied paint and PVAcet

polyvinyl butyral, were used in conservation from the 1930s until the 1960s [14]. PVAcet itself is less often reported, but has been cited as a consolidant or coating for wood [21]. Unlike $\mathrm{CN}$, this polymer has not been found widely on objects within the Division of Anthropology at the AMNH. However, Alvar, commercially manufactured by Monsanto, has an extensive history of use on fossil bone including in the Vertebrate Paleontology Preparation Laboratory at the museum, which provided the reference sample from a historic stock retained after the manufacture of this resin was discontinued in the 1960s [22].

Areas of the poles from which PVAcet-containing samples were removed, notably shinier than the rest of the surface, are characterized by an intense blue-white fluorescence emission under UV illumination. The PVAcet is localized to the lower regions of the poles, covering the unpainted section at the bottom and appearing over a few small painted areas above. This coating has been observed on other poles throughout the Hall, in areas that would have been reachable by visitors, and was likely applied to protect them from ongoing damage due to touching and vandalism. Photographic documentation by optical microscopy revealed that, at a microscopic scale, this material exhibits the same type of distinctive UV-induced fluorescence that was observed macroscopically (Fig. 5b). In some cross sections, including S1 from $16 / 567$ and S1 from 16/568, PVAcet is present in layers of sufficient thickness that its identification and exact location could be confirmed with ATR-FTIR measurements. Conservators believed this coating to be the topmost on the poles and overlying the $\mathrm{CN}$; however, this was difficult to verify analytically as, in most samples, the thin $\mathrm{CN}$ coating is not readily visible below the PVAcet. However, in cross section S1 from 16/567, removed from the bottom bare wood section of the pole in an area where previous damage had been inpainted, the stratigraphy of the two synthetic coatings is evident as the underlying $\mathrm{CN}$ is separated from the overlying PVAcet by a layer of overpaint (Fig. 5b).

In addition to the compounds mentioned above, glycerol and a series of fatty acids, indicative of the presence of a drying oil, were found by Py-GC/MS in all specimens analyzed (Fig. 4). While the identification of fatty acids along with phthalates might sometimes indicate an alkyd, based on the low amounts of phthalates detected, here this possibility seems unlikely. Also, trace amounts of protein were identified in two cases, namely S2 from 16/566 and S3 from 16/567. While displaying a complex combination of signals, FTIR spectra obtained from these samples exhibit bands at 3298, 3070, and $1534 \mathrm{~cm}^{-1}$, respectively attributable to amide A, B, and II; on the other hand, the $1653 \mathrm{~cm}^{-1}$ absorption typically assigned to amide I, in these instances, is likely obscured by an intense feature of $\mathrm{CN}$ lying in the same spectral region. Both oil and protein may either originate from the underlying paint or be ascribed to later surface treatments. Traditional Northwest Coast paints have historically been reported to be based on protein (specifically fish eggs) [7]; however, by the late 19th century, drying oils and commercially prepared colors containing them were widely available, and CCI identified both media in their analysis of Northwest Coast paints [7]. As reported by some authors, the large scale and outdoor setting for many monumental carvings may have prompted earlier and more widespread adoption of commercial paints than for small works that appear to have been sampled for the CCI project [23]. As also discussed in the following section about polychromy, barium and calcium were identified in all paints analyzed with portable XRF, and related compounds were detected with other techniques. This likely points to the presence of extenders and fillers commonly included in commercial oil paints, although 
their occurrence in traditional handmade colors cannot be ruled out.

Conservators found that the paint on these poles varied in its behavior by color: in particular, shades containing significant amounts of lead white demonstrated resistance to mechanical damage and many organic solvents that would be typical of drying oil media, while other colors, such as reds, dark browns, and blacks, could easily be abraded or solubilized even with low polarity solvents, behaving as if there was little binder present. While the use of different media or mixtures of media is a possibility, the observed sensitivity of some colors does not necessarily preclude the use of a drying oil binder, as it has been shown that the properties of oil paint can vary greatly depending on several factors including the chemical and physical nature of the pigments and other additives present [24]. Conservators also theorize that the overall sensitivity of the paints on these carvings is attributable at least in part to absorption of the binding medium into the wood upon application, since there is no evidence of a sealant or ground layer in the samples analyzed. In some cases, such as S5 from $16 / 567$, examination of the cross sections revealed that the paint did migrate into the upper cells of the wood (Additional file 2: Figure S2).

Py-GC/MS chromatograms of samples taken from unpainted sections at the bottom of the carvings also contained marker compounds indicative of drying oil. This is likely attributable to the presence of an additional museum-applied coating discovered by conservators during cleaning. This yellow-brown layer can be seen under polarized light in some cross sections (S2 from 16/565) and, more clearly, under UV illumination in others (S8 from 16/568) (Additional file 3: Figure S3). After removal of the overlying $\mathrm{CN}$ from the top figure on 16/565, an additional sample, namely S5, was removed to further investigate the composition of this coating, which in optical microscopy appears as a translucent layer with an abundance of dark inclusions, likely consisting of dirt (Fig. 6). This layer is too thin $(5-25 \mu \mathrm{m})$ for targeted investigation with ATR-FTIR, and transmission FTIR spectra of a scraping from the area showed similar components as samples removed from other locations with no PVAcet coating. While it was not possible to unambiguously confirm the composition of this coating layer with scientific analysis, a hypothesis was put forward that it may indeed consist of a drying oil based on its resistance to polar solvents and the lack of other compounds in FTIR and Py-GC/ MS data of scraped samples.

Furthermore, an oxidation product of abietic acid, namely 7-methoxy-tetradehydroabietic acid, was identified in sample S1 from 16/568 (Fig. 4); the same peak

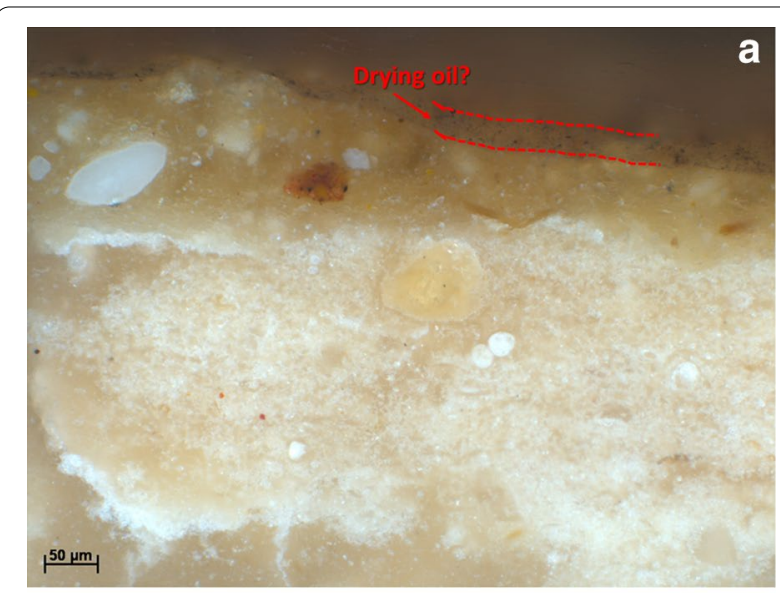

$50 \mu \mathrm{m}$

Fig. 6 a Polarized and $\mathbf{b}$ UV light microphotographs of cross section S5, i.e. coating over beige paint from a bear at the top of the pole, collected from house post 16/565 after removal of the overlying CN. The sample displays a translucent layer at top, possibly consisting of drying oil, with an abundance of dark dirt inclusions

is also present in the chromatograms obtained from all other samples, although very weak: this suggests that trace residues of a diterpenoid resin belonging to the Pinaceae family may be present. Besides being listed as a possible additive in $\mathrm{CN}$ [17], this type of resin has also been used in paints and varnishes usually in combination with linseed or another drying oil, and may be present as a residue in turpentines [25].

An abundance of inorganic materials including sulfates and silicate minerals of various compositions were also identified by transmission FTIR. In the cross sections examined, these compounds likely correspond to dirt layers originating from the accumulation of environmental particulates, dispersed within an organic grime matrix, as shown by the distribution of silicon, calcium, potassium, and sulfur in the EDS elemental maps (Fig. 7).

On the other hand, the presence of calcium oxalates, detected by FTIR, is likely due to the biodeterioration of organic materials and their reaction with 

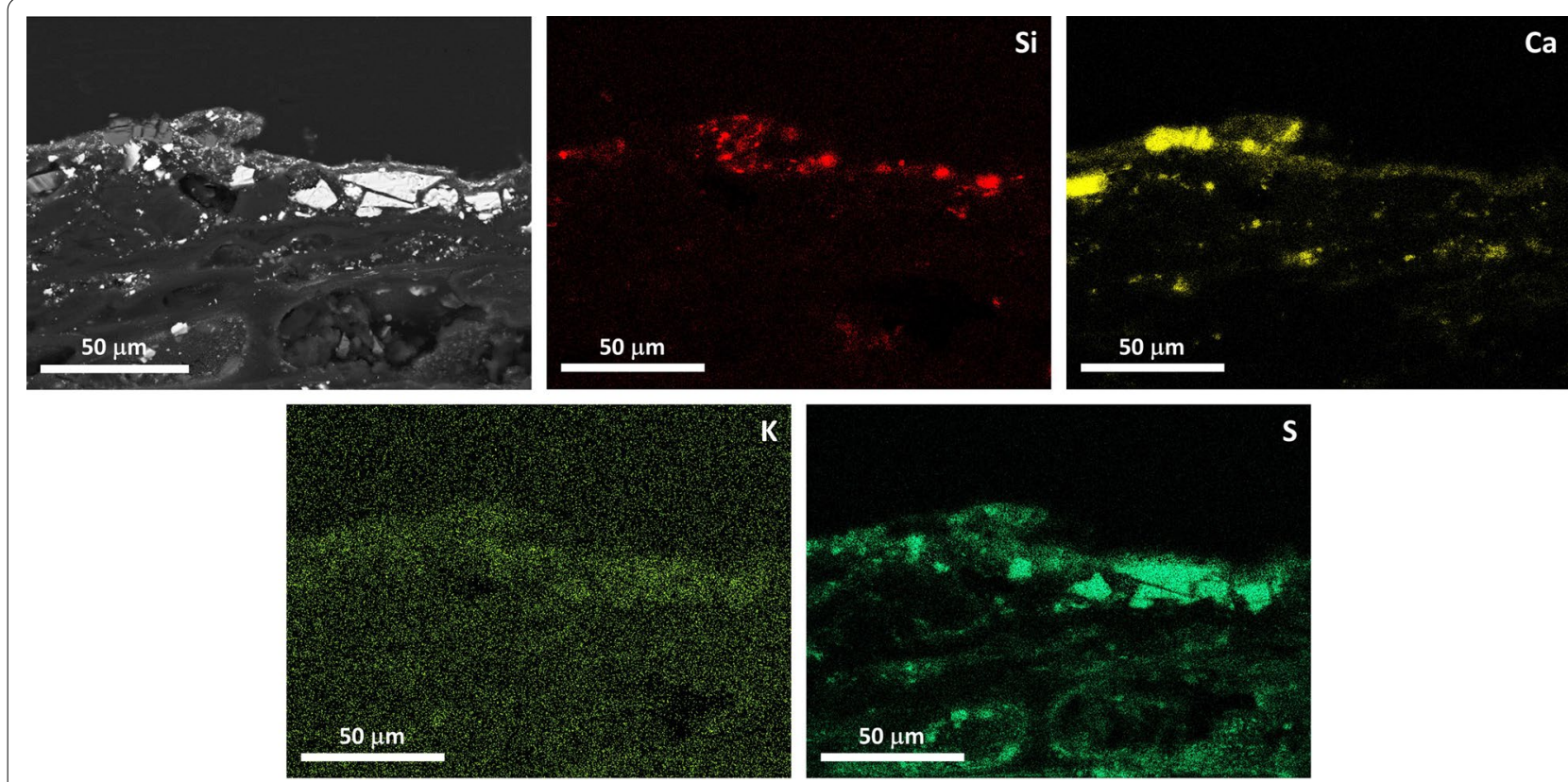

Fig. 7 BSE image and EDS elemental maps of cross section S6 from house post 16/568, i.e. "intact" area of black paint from the bear's eyebrow showing the presence of silicon-, calcium-, potassium-, and sulfur-rich dirt layers originating from the accumulation of environmental particulate, dispersed within an organic grime matrix

calcium-containing pigments or particulate dirt [26]. Similarly, the finding of metal carboxylates in most spectra probably results from the chemical reaction between the oil found in the analysis, from either the paint media or coating above, and certain pigments in the underlying paint or compounds in the adjacent dirt layers. Finally, the significant amounts of carbohydrates identified ubiquitously in the samples' chromatograms may be interpreted as products from the pyrolysis of wood. However, it cannot be ruled out that at least a fraction of the latter compounds may originate from the presence of specific polysaccharides, such as gums (previously identified in the analysis of samples from other monumental carvings in the Northwest Coast Hall) or starch (detected as a fill material in certain areas of the house posts examined in this study, as explained in the following section).

Xylamon LX-Hardening N, a commercial wood hardener manufactured by Desowag-Bayer, was used on wooden objects in the Division of Anthropology of the $\mathrm{AMNH}$ in the past and has been reportedly applied to poles in other collections as well [9]. Conservators had long suspected its presence on large carvings in the Northwest Coast Hall. This product is reported to contain an insecticide compound, lindane, dissolved in an anhydrous solvent and combined with wood preservatives and consolidants [14, 27]. A sample collected from an old can of Xylamon, found in the AMNH conservation laboratory in the 1980s and retained for future reference, was analyzed for comparison. Consistent with literature data, results showed this material to contain lindane and acrylic compounds, including methyl methacrylate and $n$-butyl methacrylate. None of these substances, however, was identified in samples removed from the four house posts in the present study.

\section{Polychromy}

Results from scientific analysis of the polychromy seen on the four house posts examined in this work are summarized in Table 2.

Analysis of the paints on all four poles revealed a color palette with a limited range of pigments, namely lead white, iron-containing earth and umber pigments, carbon-based black, vermilion, and greens composed of mixtures of Prussian blue with an undetected yellow dye. These pigments are consistent with those reported in previously published analysis, although the palette of the AMNH carvings is broader than that traditionally found in Tsimshian or other Northwest Coast artifacts, which was generally limited to black, red, and green or blue colors [7].

White, yellow, beige, and brown colors were only analyzed non-invasively by means of portable XRF spectroscopy. Whites appeared to consist mostly of lead, likely indicating the use of lead white. Light brown, beige, and yellow colors were found to also contain lead, as well as calcium, zinc, and barium, along with minor amounts 


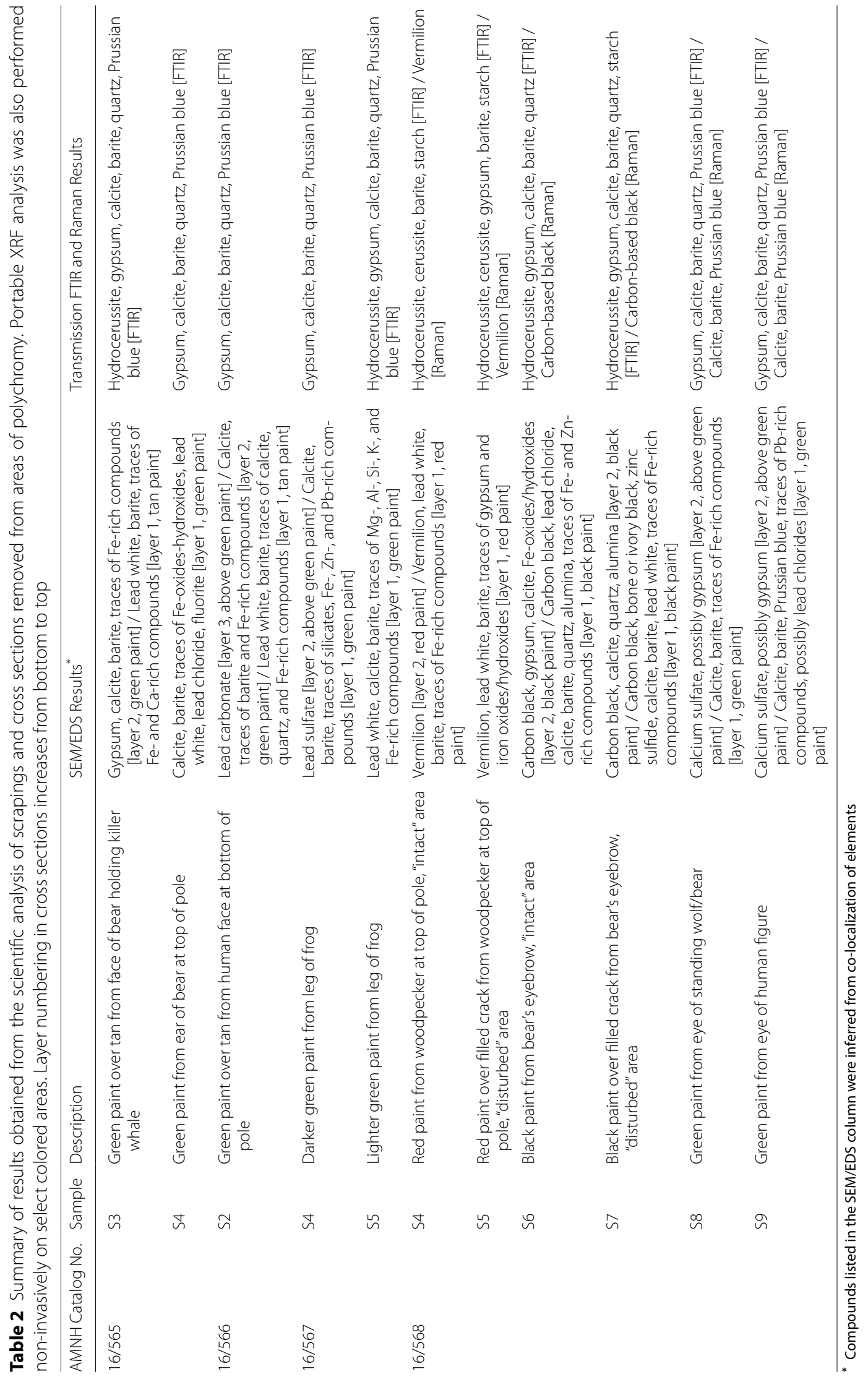


of iron, suggesting that iron oxides or hydroxides may have been mixed with white pigments to impart the faint coloring. Similarly, dark brown hues are based on ironcontaining earth and umber pigments, inferred from the detection of intense iron peaks alongside minor amounts of manganese. Black tones, yielding XRF spectra that did not display any elements that could explain the color observed, gave rise to two broad Raman signals that are attributed to a carbon-based black (Additional file 4: Figure S4a). The red hues, on the other hand, generated strong mercury peaks in XRF, suggesting that vermilion was likely used. The presence of the latter was confirmed by Raman spectroscopy (Additional file 4: Figure S4b).
$\mathrm{XRF}$ analysis of the greens showed no elements typically associated with green or yellow inorganic pigments, such as copper or chromium. However, the identification of variable amounts of iron in the data collected pointed to the possible use of Prussian blue, likely present alongside an organic yellow colorant to yield a green coloration. The presence of Prussian blue in all green tones investigated was corroborated by analysis with FTIR and Raman spectroscopies (Fig. 8a, b). When analyzed with EDS, these materials were mostly characterized by intense iron peaks, which only in one case appeared to be associated with nitrogen, possibly due to a higher concentration of pigment in the corresponding specimen

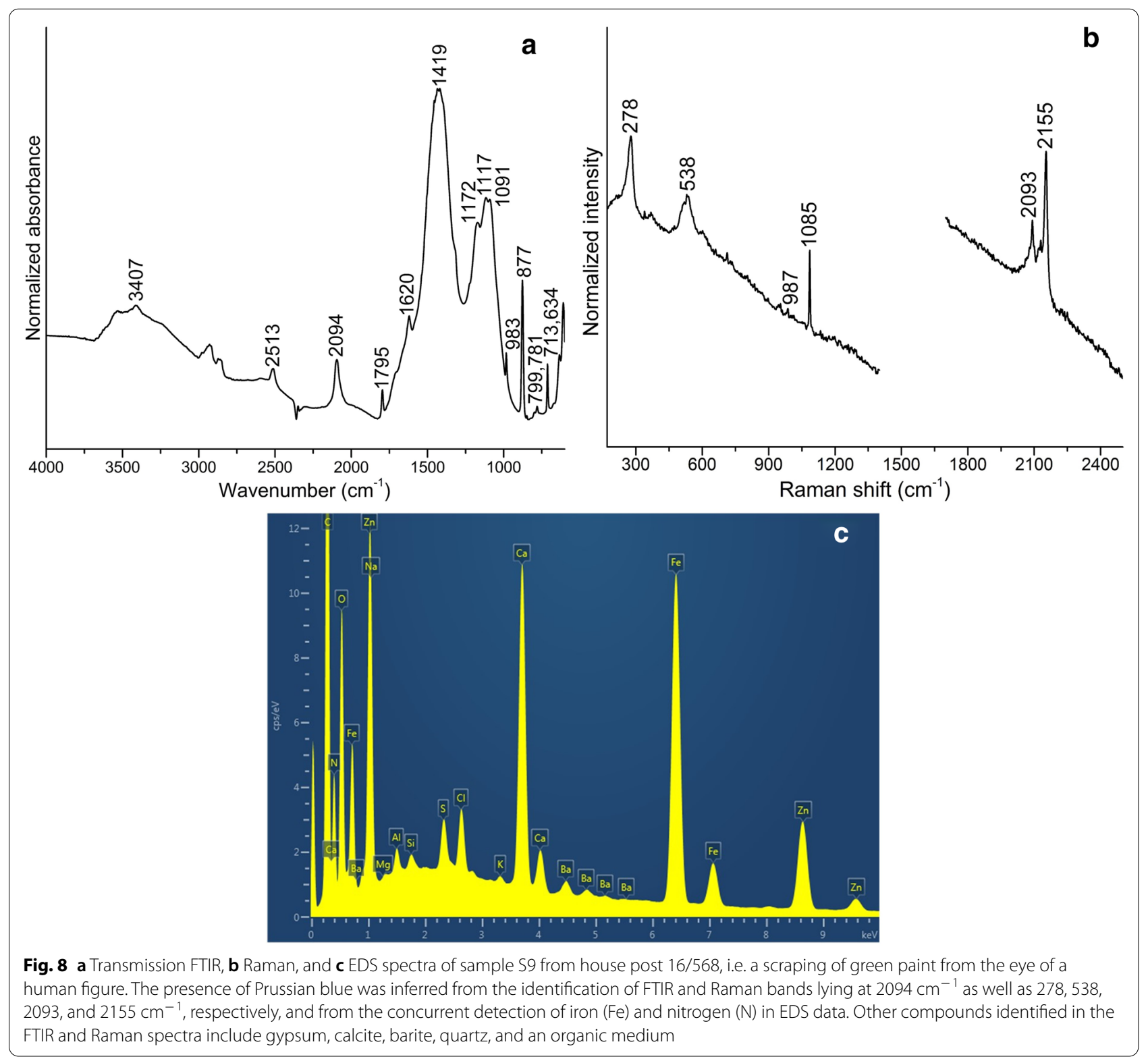


(Fig. 8c). Spectroscopic analyses showed that all the main pigments identified in the samples are mixed in with a variety of whites, including gypsum, calcite, barite, and lead white-the latter present in both forms of hydrocerussite and cerussite (Fig. 8 a, b).

According to two studies published by researchers at the CCI, Prussian blue and its mixtures are the second most widely identified greens in Northwest Coast painting, after green earth $[7,8]$. Chrome green, obtained by combining Prussian blue with chrome yellow, is the most common of the mixtures reported; despite having been detected on several other Northwest Coast carvings at the AMNH, its presence could be ruled out in this case due to the absence of chromium in the XRF and EDS spectra. The use of other inorganic yellows, such as cadmium yellow or iron-containing earth, was also deemed unlikely based on the data collected: indeed, no cadmium was detected in elemental data; no evidence of discrete yellow particles was found upon microscopic examination; and, when mixed with Prussian blue, ochers and siennas result in muddy gray-brown tones with only a slight greenish tint. The third most typically reported green in the CCI studies is listed simply as "Prussian blue" or "Prussian blue mixtures", without clear identification of the yellow component. After chrome green, the most common green associated with Prussian blue is Prussian green, also known as Hooker's green, a mixture of Prussian blue with organic yellows, white pigments, and extenders, with gamboge and the flavonoid-based dye Dutch pink as the most widely reported yellows found in these mixtures $[28,29]$. In this work, however, gamboge, which is readily identified with FTIR if present [30], was not detected in any of the spectra acquired; moreover, HPLCPDA analysis of a scraping of green paint (sample S3) from house post 16/566 did not display any organic colorants, although extraction and analysis were performed on a relatively large amount of specimen. The latter result might be due to the presence of such yellow dye in amounts below the technique's detection limits, or to the fact that it may have degraded over time. If a yellow dye is indeed present in the samples examined-likely in extremely low amounts or a degraded form-fading of this component must be considered as a potential contributing factor to the darkening of upper layers of green paint observed on the house posts, as loss of yellow would cause the green to become darker and bluer.

Macroscopic and microscopic examination of the green hues revealed that their texture and topology were distinct and more varied than those of other colors on the four house posts. Except for S2 from 16/566, characterized by fine and homogeneous grain size, greens were found to be generally more granular than most other shades, and often presented thicker "pooled" areas of paint at the edges of shapes, such as the facial marking on many of the figures. Special attention was devoted to a careful examination of the cross section stratigraphy in an attempt to clarify whether multiple layers of green paint might be present. Two samples were taken from the frog on pole 16/567-the only figure painted green overall. During macroscopic examination, two distinct shades of green were noted: a darker green appearing on the top surfaces of the frog, and a lighter green on its underside, mimicking the natural coloration of these creatures. It appeared that the darker green may have been layered on top of the lighter green. As the use of multiple shades of a color within a single design element and layering of colors is not usually found in Northwest Coast art, conservators targeted this area for investigation (Additional file 5: Figure S5). Upon optical microscopy and SEM/EDS examination, all the cross sections of green paint, including the dark (S4) and light (S5) greens on the frog of house post $16 / 567$, unequivocally displayed only one layer of paint (Additional file 6: Figure S6). Scientific analysis thus ruled out the hypothesis of intentional layering of paint by the artist or later intervention as a possible source for the dark surface appearance of the green colors. The thin, darker layer visible at the top of all green cross sections, instead, is likely attributable to the accumulations of coatings and soiling that appear to diffuse into the paint layer in several samples (Additional file 7: Figure S7).

Further observations revealed that some longitudinal drying cracks in the wood were filled with a white material. Though often cupped and flaking, the paint over the fill appeared consistent in color and texture with paint in adjacent areas applied directly to the wood. However, the dramatic difference in condition led conservators to question if the filled areas were part of the original fabrication or a later restoration campaign (Additional file 8: Figure S8). To investigate this issue, samples of red and black paint were removed from pole 16/568, which showed extensive areas of cracking and associated disrupted paint surface. In both cases, two specimens were taken from each color-the first from an "intact" area away from the crack, and the second in a "disturbed" area of paint on or near the filled crack. In cross sections from the disturbed areas, namely the red of the woodpecker (S5) and the black eyebrow of the bear (S6), a continuous layer of material can be seen between the paint and the wood, appearing translucent in polarized light and bright white under UV illumination (Fig. 9a, b). SEM/ EDS analysis determined that such a layer was organic and composed of an abundance of tightly packed oval granules (Fig. 9c, d), whose morphology and size (semi-major axis ranging from 5 to $20 \mu \mathrm{m}$ ) is compatible with that of some starches including potato starch [31-33], often listed in historic recipes as fillers for wood and other materials [34]. More localized islands of this same material were also noted 

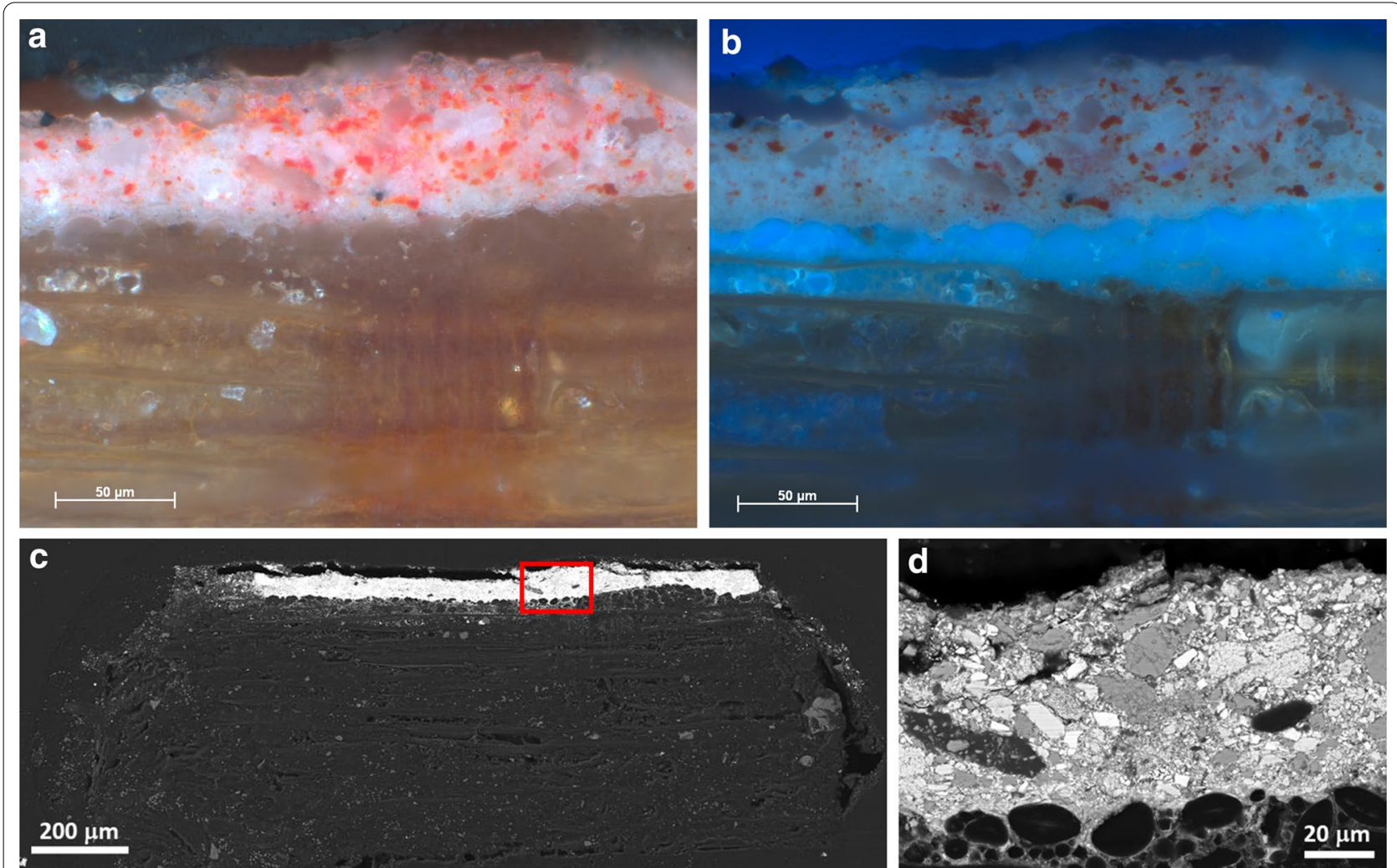

Fig. 9 a Polarized and $\mathbf{b}$ UV light microphotographs, as well as c, d BSE images of cross section S5 from house post 16/568, i.e. "disturbed" area of red paint over filled crack from a woodpecker at the top of the pole. These images reveal a continuous layer of material between the paint and the wood, appearing translucent in polarized light and bright white under UV illumination. EDS data determined that such a layer was organic and composed of an abundance of tightly packed oval granules

in three additional cross sections, i.e. S3 from 16/565, as well as S4 and S9 from 16/568. Analysis with FTIR unambiguously confirmed the presence of starch in samples S4, S5, and S7 from house post 16/568 (Additional file 9: Figure S9). As this fill appears to be always located directly onto the wood and under all paint layers in the samples examined, it is likely to have been applied at the time of the overall painting. Interestingly, three of the four cross sections removed from these areas showed two layers of red or black paint, both of which are consistent in composition with the paint in areas away from the crack. Also, there is no grime or other separation between the paint layers to indicate that the thinner top ones were a later application; therefore, it is more likely that these were applied by the artist in regions overlying the white fill material in order to match the overall color.

\section{Cleaning treatment}

The information provided by scientific analysis assisted conservators in achieving a fuller understanding of the surface of the Tsimshian house posts, in terms of both original materials and methods of manufacture and museum-applied coatings. Awareness that the starchfill extended under the overall paint, and thus was not a post-collection restoration, reinforced the conservators' inclination to stabilize the cupped and flaking areas of paint, rather than remove and replace them, as might be done in the case of a degraded museum restoration. The work performed also supported decision-making regarding how the surface was cleaned. To remove obscuring coatings and soiling, conservators employed aqueous solutions and solvents, both independently and combined into a system of macroemulsions stabilized by the addition of a viscosity modifier, adapting established techniques widely used for cleaning paintings $[35,36]$. In addition, more recently developed systems of microemulsions and functional gels were utilized to target specific issues not successfully addressed with the other systems [37, 38]. Identification of the coatings allowed conservators to pinpoint specific solvents or solvent combinations with the closest solubility parameters to remove $\mathrm{CN}$ and PVAcet. Information regarding the composition of the paints enabled the team to determine the target $\mathrm{pH}$ range and 


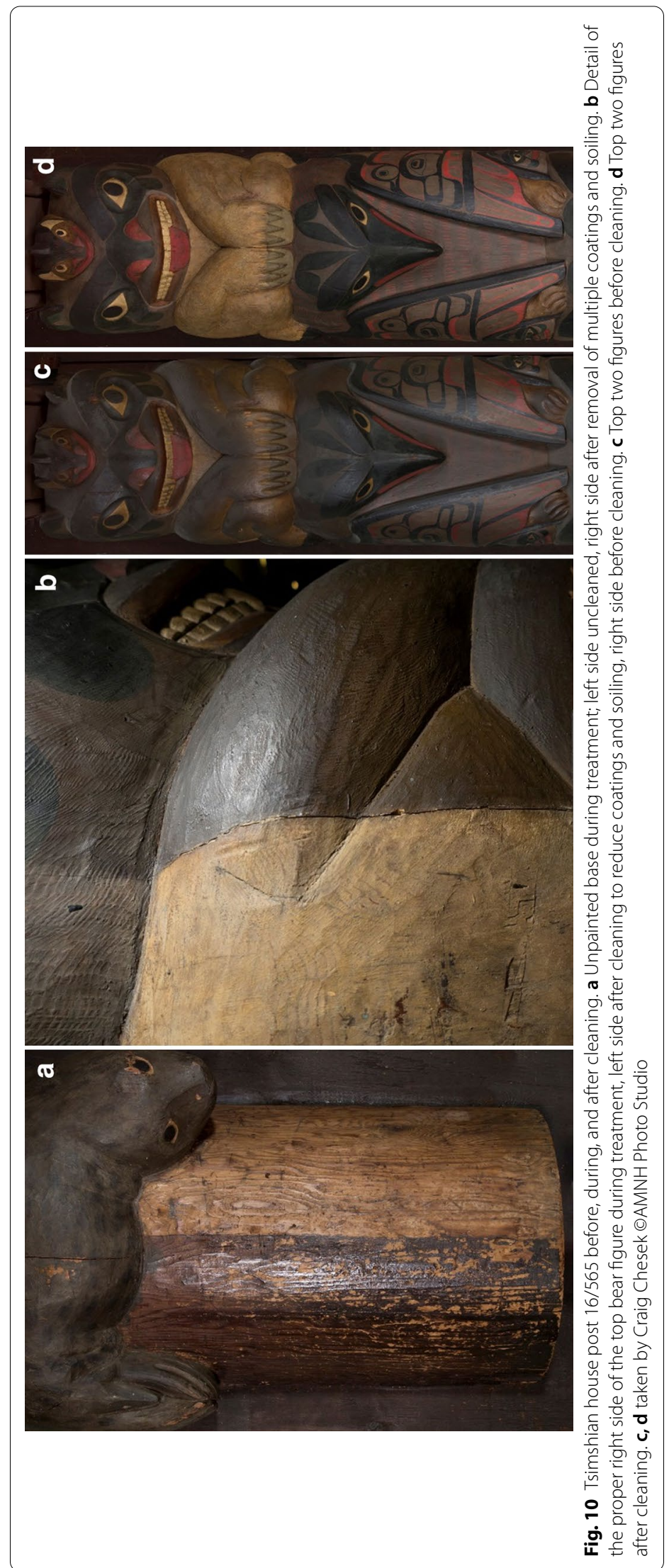


types of chelators that could be employed safely. The resulting treatment greatly improved the appearance and readability of the polychromy (Fig. 10).

\section{Conclusions}

The present article describes a collaborative endeavor for the scientific analysis of a group of four elaborately painted 19th-century Tsimshian house posts at the AMNH. On continuous open display in the museum's Northwest Coast Hall for over a century, these poles had accumulated surface grime and several coating layers applied in undocumented past restoration efforts, which had darkened and yellowed with ageing. An extensive campaign of close examination and technical investigations was undertaken in support of the ongoing cleaning intervention with two main objectives: first, to address questions about the number, composition, and order of coating applications; and second, to answer queries regarding the polychromy that came up during treatment, with a focus on green colors and areas of disrupted paint associated with fills.

Analysis of scrapings and cross sections removed from eleven areas of coating with micro-invasive techniques, mostly Py-GC/MS and FTIR, revealed multiple layers consisting of cellulose nitrate, polyvinyl acetal, as well as a third organic material that was tentatively identified as drying oil based on its observed physical characteristics. Besides these layers, often present in combination and intermixed with dirt and paint, a few other organic compounds were identified in some of the samples: most notably, protein, which, along with the oil, may either originate from the underlying paint or be ascribed to later surface treatments. XRF, Raman, FTIR, and SEM/ EDS analysis of eleven additional samples collected from various polychromed areas showed a color palette composed of a limited range of pigments, including lead and zinc whites, iron-containing earth and umber pigments, vermilion, and Prussian blue-the latter possibly mixed with an undetected yellow dye. The data collected clearly demonstrated that the green paint, initially appearing to involve an overlapping of lighter and darker shades on pole 16/567, actually consists of a single layer. Furthermore, examination of the paint near drying cracks in the wood revealed that a starch fill layer is present in several samples. Located between the wood and paint, this layer was likely applied at the time of the original painting. Cross sections removed from disrupted areas showed two layers of red and black paint, both of which, however, are consistent in composition with the paint in areas away from the cracks, and are thus likely to have been applied at the same time as the application of the fill material and overall painting of the poles.
Results from this technical study helped inform the development and optimization of a suitable conservation treatment tailored to the safe removal or reduction of surface coatings and grime from a remarkable group of historical Tsimshian house posts, ultimately improving the legibility of their design and colors. Moreover, the data collected in this work represent a valuable addition to the extant scholarship on Northwest Coast monumental carvings, providing conservators, scientists, and scholars with a useful resource on this understudied topic.

\section{Abbreviations}

XRF: X-ray fluorescence spectroscopy; FTIR: Fourier-transform infrared spectroscopy; ATR-FTIR: Attenuated total reflection-Fourier-transform infrared spectroscopy; SEM/EDS: Scanning electron microscopy with energy-dispersive X-ray spectroscopy; BSE: Back-scattered electron; Py-GC/MS: Pyrolysis-gas chromatography / mass spectrometry; HPLC-PDA: High-performance liquid chromatography with photodiode array detection.

\section{Supplementary Information}

The online version contains supplementary material available at https://doi. org/10.1186/s40494-021-00513-4.

Additional file 1: Fig. S1. Location of samples removed from the AMNH Tsimshian house posts in this study. Line drawings by Kayla D. Younkin, 2018.

Additional file 2: Fig. S2. Polarized light microphotograph of cross section S5 from house post 16/567, i.e. light green paint from the leg of a frog, clearly showing that the paint migrated into the upper cells of the wood.

Additional file 3: Fig. S3. Polarized light microphotograph of cross section S2 from house post $16 / 565$, i.e. coating over gray paint from a seal at the bottom of the pole, and $\mathbf{b}$ UV light microphotograph of cross section S8 from house post $16 / 568$, i.e. green paint from the eye of a standing wolf or bear, showing a brown-yellow layer of presumed drying oil just underneath the samples' surface.

Additional file 4: Fig. S4. Raman spectra of a sample $\$ 6$ from house post 16/568, i.e. "intact" area of black paint from the bear's eyebrow, and b sample 54 from house post 16/568, i.e. "intact" area of red paint from a woodpecker at the top of the pole. In spectrum $\mathbf{a}$, bands at $\approx 1335$ and $\approx 1575 \mathrm{~cm}^{-1}$ are assigned to a carbon-based black. In spectrum $\mathbf{b}$, bands at 252,284 , and $343 \mathrm{~cm}^{-1}$ are attributed to vermilion.

Additional file 5: Fig. S5. Proper left side of the frog figure on 16/567 after treatment, showing two shades of green paint.

Additional file 6: Fig. S6. a Polarized and b UV light microphotographs, as well as c BSE image of cross section $S 4$ from house post 16/567, i.e. dark green paint from the leg of a frog, unequivocally displaying only one layer of paint.

Additional file 7: Fig. S7. UV light microphotograph of cross section S3 from house post 16/565, displaying diffusion of soiling into the paint layer.

Additional file 8: Fig. S8. A detail of cupping and flaking red paint over fill material, from the top woodpecker figure of house post 16/568.

Additional file 9: Fig. S9. Transmission FTIR spectra of sample S5 from house post 16/568, i.e. "disturbed" area of red paint over filled crack from a woodpecker at the top of the pole. Bands at 3365, 2933, 1652, 1153, 1079, and $1022 \mathrm{~cm}^{-1}$ are attributed to starch. 


\begin{abstract}
Acknowledgements
The authors from the AMNH are grateful for the opinions and guidance of consulting curators to the Northwest Coast Hall renovation project, especially David Boxley (Tsimshian of Metlakatla; master carver) and Xsim Ganaa'w (Laurel Smith Wilson; Gitxsan, Fireweed Clan, House of Guuxsan; former director and curator of the 'Ksan Historical Village and Museum, Hazelton), as well as co-curators for the Hall Haa'yuups (Ron Hamilton; Nuu-chah-nulth artist and cultural historian) and Peter Whiteley (AMNH curator of North American Ethnology). They also acknowledge the invaluable contributions of Julia Sybalsky and Jessica Walthew, who were involved in the initial stages of examination and analysis of the poles; Gabrielle Tieu and Fran Richie, who conducted portable XRF analysis; and the many conservators who have participated in the treatment and documentation. FP would also like to acknowledge Dr. Anna Cesaratto for her contribution to this project during her time at The Met working in the NICS program.
\end{abstract}

\section{Authors' contributions}

FP coordinated the study, removed samples, mounted the cross sections, carried out optical microscopy, transmission FTIR, ATR-FTIR, Raman, Py-GC/MS, and HPLC-PDA analysis and data interpretation, as well as drafted the manuscript with inputs from all other authors. EB conducted SEM/EDS analysis and interpreted the results. SAld aided in data interpretation. SAld and JL provided background information on the carvings and, along with MN and SA, they supported the scientific work and helped with drafting of the manuscript. All authors read and approved the final manuscript.

\section{Funding}

This research was made possible by the Network Initiative for Conservation Science (NICS), a Metropolitan Museum of Art program. Support for NICS was provided by a grant (31500630) from The Andrew W. Mellon Foundation. Support for the project to treat the six painted monumental carvings from the Northwest Coast Hall at the AMNH was provided by a grant (MA_30-17-026017) from the Institute for Museum and Library Services, and collaborative work with First Nations curators and advisors was supported by a grant (41600654) from The Andrew W. Mellon Foundation.

\section{Availability of data and materials}

All data generated during this study are either included in this published article or available from the corresponding author upon reasonable request.

\section{Declarations}

\section{Competing interests}

The authors declare that they have no competing interests.

\section{Author details}

${ }^{1}$ Department of Scientific Research, The Metropolitan Museum of Art, 1000 Fifth Avenue, New York, NY 10028, USA. ${ }^{2}$ Department of Conservation, Division of Anthropology, American Museum of Natural History, Central Park West at 79th street, New York, NY 10024, USA. ${ }^{3}$ Department of Conservation, Museum Resources Division, New Mexico Department of Cultural Affairs, 725 Camino Lejo, Santa Fe, NM 87505, USA. ${ }^{4}$ S.A. Art Conservation LLC, 77 Rose Street, Hastings on Hudson, NY 10706, USA.

\section{Received: 21 January 2021 Accepted: 25 March 2021}

Published online: 09 April 2021

\section{References}

1. Lévi-Strauss C. Totemism. Boston: Beacon Press; 1963.

2. Lévi-Strauss $C$. The way of the masks. Seattle: University of Washington Press; 1975.

3. Halpin MM. Totem poles: an illustrated guide. Vancouver: UBC Press; 1981.

4. Boas F. Tsimshian mythology. 31st Annual Report of the Bureau of American Ethnology for 1909-1910. Washington, Government Printing Office, $1916 ; 483-88$.
5. Boas F. The decorative art of the Indians of the North Pacific Coast. Bulletin of the American Museum of Natural History Vol. 9, Article 10, 1897 : 123-76.

6. Levinson J, Alderson S, Tieu G, Knauer K. Painted totem poles at the American Museum of Natural History: treatment challenges and solutions. In: Postprints of the Joint Session of the AIC Paintings and Wooden Artifacts Specialty Groups, 42nd Annual Meeting of the American Institute for Conservation, San Francisco, California, 2014; p. 15-28.

7. Miller J, Moffatt E, Sirois J. CCI Native materials project: final report. Ottawa: Analytical Research Services, Canadian Conservation Institute, Department of Communications, Government of Canada; 1990

8. Wainwright INM, Moffatt EA, Sirois PJ. Occurrences of green earth pigment on Northwest Coast first nations painted objects. Archaeometry. 2009;51(3):440-56.

9. Cooper M, Solajic M, Usher G, Ostapkowicz J. The application of laser technology to the conservation of a Haida totem pole. J Cult Herit. 2003;4:165-73.

10. Kirby J, White R. The identification of red lake pigment dyestuff and a discussion of their use. National Gallery Technical Bulletin. 1996;17:56-80

11. Wouters J, Verhecken A. The coccid insect dyes: HPLC and computerized diode-array analysis of dyed yarns. Stud Conserv. 1989;34(4):189-200.

12. Mouri C, Laursen R. Identification and partial characterization of C-glycosylflavone markers in Asian plant dyes using liquid chromatography-tandem mass spectrometry. J Chromatogr A. 2011;1218(41):7325-30.

13. Selwitz CM. Cellulose nitrate in conservation. Los Angeles: Getty Publications; 1988.

14. Horie CV. Materials for conservation: organic consolidants, adhesives and coatings, second edition. London and New York: Routledge; 2010.

15. Schwarzinger C, Tanczos I, Schmidt H. Pyrolysis-gas chromatography/ mass spectrometry and thermally assisted hydrolysis and methylation (THM) analysis of various cellulose esters. J Anal Appl Pyrol. 2001;58:513-23.

16. Edge M, Allen NS, Hayes M, Riley PN, Horie CV, Luc-Gardette J. Mechanisms of deterioration in cellulose nitrate base archival cinematograph film. Eur Polym J. 1990;26(6):623-30.

17. Meincke A, Hausdorf D, Gadsden N, Baumeister M, Derrick I, Newman R, Rizzo A. Cellulose nitrate coatings on furniture of the Company of Master Craftsmen. J Am Inst Conserv. 2009;48(1):1-24.

18. Horrocks AR, Price D, editors. Advances in fire retardant materials. Cambridge: Woodhead Publishing Limited; 2008.

19. Simpson-Grant M. The use of ultraviolet induced visible-fluorescence in the examination of museum objects, part 2. Conserve O Gram 2000; $1(10)$

20. Moldoveanu SC. Analytical pyrolysis of synthetic organic polymers. San Diego: Elsevier; 2005.

21. Spirydowicz KE, Simpson E, Blanchette RA, Schniewind AP, Toutloff MK, Murray A. Alvar and Butvar: the use of polyvinyl acetal resins for the treatment of the wooden artifacts from Gordion, Turkey. J Am Inst Conserv. 2001;40(1):43-57.

22. Howie FMP. Materials used for conserving fossil specimens since 1930: a review. Stud Conserv. 1984;29:92-7.

23. Keithahn EL. Monuments in cedar. R. Anderson, Ketchikan, Alaska; 1945.

24. Bonaduce I, Duce C, Lluveras-Tenorio A, Lee J, Ormsby B, Burnstock A, van den Berg KJ. Conservation issues of modern oil paintings: a molecular model on paint curing. Acc Chem Res. 2019;52:3397-406.

25. Mills JS, White R. The Organic Chemistry of Museum Objects. Butterworth-Heinemann; 1994.

26. Sutherland K, Price B, Lins A, Passeri I. Oxalate-rich surface layers on paintings: implications for interpretation and cleaning. In: Mecklenburg MF, Charola AE, Koestler RJ, editors. New insights into the cleaning of paintings. Washington DC: Smithsonian Institution Scholarly Press; 2013. pp. $85-7$.

27. Unger A, Schniewind AP, Unger W. Liquid wood preservatives. In: Unger A, Schniewind AP, Unger W, editors. Conservation of wood artifacts: a handbook. Berlin: Springer; 2001. pp. 165-274.

28. Berrie B. Prussian Blue. In: Artists' pigments: a handbook of their history and characteristics. Vol. 3, 2012. p. 191-218.

29. Harley RD. Artists pigments C. 1600-1835: a study in English documentary sources. London: Butterworth Scientific; 1982. 
30. Berrie B, Casadio F, Dahm K, Strumfels Y, Tedeschi M, Walsh J. A vibrant surface: investigating color, texture and transparency in Winslow Homer's watercolors. In: Science and Art 2014; p. 404-410.

31. Jane $J \mathrm{~L}$, Shen JJ. Internal structure of the potato starch granule revealed by chemical gelatinization. Carbohydr Res. 1993;247:279-90.

32. Jackson DS. Starch. In: Caballero B, Trugo L, Finglas P, editors. Encyclopedia of food science and nutrition. San Diego: Academic Press; 2003. pp. 5561-76.

33. Singh J, Singh N. Studies on the morphological and rheological properties of granular cold water soluble corn and potato starches. Food hydrocoll. 2003;17(1):63-72.

34. Thornton J. A brief history and review of the early practice and materials of gap-filling in the West. J Am Inst Conserv. 1998;37(1):3-22.

35. Stavroudis C, Doherty T, Wolbers R. A new approach to cleaning I: using mixtures of concentrated stock solutions and a database to arrive at an optimal aqueous cleaning system. WAAC Newslett. 27(2) (n.d.):17-28.
36. Wolbers R. Cleaning painted surfaces: aqueous methods. London: Archetype Publications; 2000.

37. Baglioni P, Chelazzi D, Giorgi R. Nanotechnologies in the conservation of cultural heritage: a compendium of materials and techniques, 2015.

38. Chelazzi D, Giorgi R, Baglioni P. Microemulsions, micelles, and functional gels: how colloids and soft matter preserve works of art. Angew Chem Int Ed. 2018;57:7296-303.

\section{Publisher's note}

Springer Nature remains neutral with regard to jurisdictional claims in published maps and institutional affiliations.

\section{Submit your manuscript to a SpringerOpen ${ }^{\circ}$ journal and benefit from:}

- Convenient online submission

- Rigorous peer review

- Open access: articles freely available online

- High visibility within the field

- Retaining the copyright to your article

Submit your next manuscript at $\boldsymbol{\nabla}$ springeropen.com 